\title{
Ethical issues after pre-natal diagnosis
}

\author{
Antonio F. Corno \\ Houston Children's Heart Institute, Memorial Hermann Children's Hospital, University Texas Health, McGovern Medical School, Houston, TX, USA \\ Correspondence to: Antonio F. Corno. Research Professor, Houston Children’s Heart Institute, Memorial Hermann Children's Hospital, University \\ Texas Health, McGovern Medical School, Houston, TX 77030, USA. Email: tonycorno2@gmail.com.
}

\begin{abstract}
Following pre-natal diagnosis of congenital heart defect parents and family face a dramatic psychological crisis because of their state of shock, contradictory information available on potential outcomes, limited availability of time for decisions and for autonomous choices. Counselling the parents can present additional difficulties due to influence of education, cultural and religious background, individual cognitive and emotional processes, and cross-cultural patient care is a challenging issue for the caregivers. Type and quality of messages transmitted by the caregivers determine the counselling process, with the risk of misunderstandings particularly high with reduced available evidence, or with different outcomes accordingly with the various alternatives of treatment. Since the introduction of pre-natal diagnosis for congenital abnormality, interruption of pregnancy became available on these grounds in many Western countries, and the numbers of babies born with congenital heart defects has declined significantly despite concomitant advances in treatment options and outcomes. Detailed and objective information, with all available options, should be provided after pre-natal diagnosis of congenital heart defect. One of the major achievements of pediatric medicine in the last 50 years is the increased understanding of the pathogenetic causal mechanisms of congenital heart defects as well as its treatment. For congenital heart defects the progress of surgical treatments allowed a huge proportion of these children to reach adult life with a decent quality of life and social integration. Therefore, must be a considerable concern that universal pre-natal diagnosis widespread pregnancy interruption may obviate those gains. A reduction in the post-natal population undergoing treatment may have a significantly deleterious effect on the expertise of the caregivers, producing a reduction in outcome quality. With all respect for the parental choices and the obligations to follow the national laws, is necessary to remark that our society is genuinely ambivalent.
\end{abstract}

Keywords: Congenital heart defects; counselling; ethics; interruption of pregnancy; pre-natal diagnosis

Submitted May 15, 2020. Accepted for publication Aug 05, 2020.

doi: $10.21037 /$ tp-20-141

View this article at: http://dx.doi.org/10.21037/tp-20-141

\section{Introduction}

Pre-natal diagnosis of congenital heart defects relies on several elements, such as equipment, specific expertise, local structure and infra-structure, all factors variable among countries and over time, as services and policies evolve, and therefore affecting rate and impact of fetal screening (1-3). In any case, the incidence of pre-natal diagnosis is influencing the trends and outcomes of congenital heart defects, and several additional factors have to be included in the evaluation of the outcomes: associated non-cardiac co- morbidities, pregnancy management and delivery planning, long-term neurodevelopmental consequences, resources utilization and costs/benefits issues.

Various reports have taken in consideration all various points listed above, and the unavoidable relationships among them (4-17); their correlation is very strict, even if it is impossible to quantify the sensitivity/specificity of the fetal screening or the subsequent outcome (18-29).

The matter becomes even more delicate when considering all potential ethical implications of fetal finding of heart malformation, particularly regarding parents 
counselling and interruption of pregnancy versus treatment.

When dealing with ethical issues following pre-natal diagnosis, it should be advisable to distinguish between complex and simple cardiac malformations.

\section{Complex congenital beart defects}

The largest group of complex congenital heart defects includes all malformations with "functionally" univentricular heart, regardless their morphologic characteristics.

The results recently achieved in univentricular hearts have substantially improved (30-34), however the definition of "intractable" cardiac malformation remains attached to the diagnosis of univentricular heart, due to the questionable late outcomes $(12,24)$. "Intractable" (12) or "uncorrectable" (24) defines a cardiac malformation not suitable to bi-ventricular repair, but only to multi-staged complex palliations towards Fontan circulation, or heart transplant. Avoidance of treatment and compassionate care remains the only available option in these patients $(12,24)$.

Evident discrepancies exist in the literature about the various outcomes obtained with heart transplantation after the different stages of surgical management of univentricular hearts (35-38).

After fetal diagnosis of univentricular heart $(4-6,8,14,15,19,21,22,24,25,28,39)$, the decisionmaking process has been oriented towards for pregnancy termination or compassionate care in $8 \%$ of cases (19), through $16 \%(5,6), 30(14,15), 33 \%$ (4), reaching $47 \%(28)$, due to one or more of the following reasons: low hospital survival, impaired quality of life, child suffering $(8,14)$, stress for the entire family, including siblings $(8,24)$, association of genetic abnormalities and/or severe non-cardiac defects (28).

After fetal diagnosis of complex congenital heart defect a comprehensive multi-specialties pre-natal screening, including chromosomes assessment, complete intraand extra-cardiac evaluation, to provide the family with an appropriate explanation of the expected future $(5-7,14-17,19,21,24,29,39)$. The parents and their families have the right to receive all data useful to prepare and support them (24).

Following pre-natal diagnosis of congenital heart defect parents and family face a dramatic psychological crisis because of their state of shock, contradictory information available on potential outcomes, limited availability of time for decisions and for autonomous choices $(8,39)$. Furthermore, not all the parents wish to perform autonomous choices due to family or other societal pressures (8).

Counselling the parents, already complicated by the communications between healthcare providers and families, can present additional difficulties due to education, cultural and religious background, individual cognitive and emotional processes $(9,10,24,26,39)$. Cross-cultural patient care is a challenging issue for the caregivers: dealing with families rejecting medical treatments because of their educational and/or religious backgrounds requires an open mind to successfully propose a medical plan $(10,26,39)$.

Nowadays many families can become aware of the best outcomes of the top hospitals, while the same excellence not necessarily can be achieved by their local services. At this point it can be quite uncomfortable for a doctor to explain to prospective parents that the local results for complex congenital heart defects may be less satisfactory than the gold standards reported on internet, and this can also skew subsequent discussions (39).

Quite familiar is the notion of how influent are the modalities of communications transmitted by the physicians during the counselling process, as well as the perceiving mode of the parents. While it is not surprising that optimistic surgeons are capable of attracting the parents approval for surgical approach, totally unexpected is the negative reaction not infrequently shown by families after the advice received by physicians $(16,17,22-24,29,39)$.

The belief of caregivers can range between extreme optimism on the possible long-term outcomes and advice to seriously take the possibility of abortion into consideration, with obvious influence on the decisions of the parents $(11,20,22,25,27,39)$.

Fully focused attention should be given to the sensitivity of each case, particularly considering that within each couple of parents and family there are various degrees of capability to accept a poor quality of life.

The suggestions made by the doctors are generally on line with the goal of maximizing the possibilities of achieving the best outcomes, without always providing details about the chances of negative outcomes; furthermore, their knowledge on expected outcomes are biased by their previous clinical experiences $(11,39)$.

The risk of misunderstandings in the transmission of information is particularly high with reduced available evidence, or with different treatments available with variable reported results (11). Finally, due to the difficulty of prenatal screening in complex congenital heart defects and the large variation in the reported results, it can be extremely challenging for the physicians to maintain a scientific and 
Table 1 Results of the "Audience Response Survey"

\begin{tabular}{lcc}
\hline Options & Patient & Family member \\
\hline Norwood & $73 \%$ & $26 \%$ \\
Heart transplant & $0 \%$ & $1 \%$ \\
Compassionate care & $6 \%$ & $5 \%$ \\
Pregnancy interruption & $21 \%$ & $68 \%$ \\
\hline
\end{tabular}

objective approach untainted by their personal feelings and opinions (39).

Sometimes doctors are asked the following question: "What if it were your child?" (13). At the first joint meeting of the European Association Congenital Heart Surgeons and the "Congenital Heart Surgeons Society" of North America, the "Audience Response Survey" tried answering the above question interrogating experienced professionals in congenital cardiac surgery, with their answers reported in Table $1(18,39)$.

The congenital heart surgeons participating to the survey provided striking different answers between the option suggested for a pre-natal diagnosis of hypoplastic left heart syndrome in a patient versus a hypothetical close member of their family $(18,39)$.

In the all parents, families, and all the health professional involved, the fetal diagnosis of complex congenital cardiac malformation is always followed by important consequences (39).

The counselling of the parents and the entire decisionmaking process is very challenging due to the large variability of malformations with different clinical presentation, association of genetic abnormalities, presence of other intra- or extra non-cardiac defects, and the reported poor outcomes. Evidence provided by studies on the managements used nowadays should give adequate knowledge to facilitate the parents counselling after prenatal diagnosis of complex congenital heart defects.

\section{Simple congenital beart defects}

The ethical considerations become even more controversial in the presence of fetal diagnosis of simple cardiac malformations.

Since the introduction of pre-natal diagnosis for congenital abnormality, interruption of pregnancy has become available on these grounds in many Western countries. As a consequence, in some of these countries, the numbers of babies born with simple congenital heart disease has declined significantly despite concomitant advances in treatment options and outcomes, as reported on the database of the European Congenital Heart Surgery Association (https://echsacongenitaldb.org) and of the North America STS Congenital Heart surgery database (www.sts.org/registries-research-center/sts-nationaldatabase/sts-congenital-heart-surgery-database). This is the result of policies applied and reported, with debatable decision-making processes after fetal diagnosis of simple congenital heart defects (40).

The discrepancy between pre- and post-natal diagnosis of congenital heart defects occurs with a relatively low incidence but, when present, may change both the treatment both immediately after birth and the long-term management (41). Therefore, clinicians should show some caution during pre-natal counselling regarding the planned treatment based on the fetal echocardiogram, particularly when interruption of pregnancy is under consideration (41).

The reported study (40) reflects the experience in a country with a level of socio-economic and health organization among the most advanced in the world, with a particular social demographic which may be quite different even from many other high-income countries. The facts presented may well pose significant questions to be accepted or indeed understood in other health care systems with completely different levels of socio-economic status and health care, and among other cultures, religions, educations, and ethnicities $(9,10,24,26,39)$.

In particular, interruption of pregnancy has been offered for pre-natal diagnosis of congenital heart defects not as complex as the "functionally" univentricular hearts, but such as aortic coarctation, atrioventricular septal defect, tetralogy of Fallot, double outlet right ventricle, truncus arteriosus, transposition of the great arteries, and aortic arch interruption (40), all malformations with recognized low STAT risk stratification (42) and excellent outcomes, with reported mortality lower than 5\% (43).

When the decision-making has to take in account scientific as well as ethical aspects, the process becomes complicated by different perspectives.

Since the natural history of some congenital heart malformations may results in spontaneous abortion, before the availability of this information families and caregivers have to choose between medical management and abortion. The availability of termination of pregnancy completely influences the approach of physicians in these situations (44).

In a genuinely ambivalent society praising the option that 
in the near future doctors will suppress patients even with very simple congenital heart defects instead than offering them treatment, the medical profession has to deal with the opinion that some life is not worthy to be lived (44).

To be a doctor is not privilege: it is a commitment, with patients, families and community, requiring every possible effort to help the diseased people, and to push the boundaries of knowledge, with a work ethic far beyond that of research alone (45).

Interruption eliminates the fetus with a malformation, it doesn't cure the underlying malformation. Thus, interruption of pregnancy doesn't address the defect, and doesn't care the affected individuals (45). Our responsibility is to develop a science without cultural stagnation, but to encourage research, and to involve not only patients and families, health organizations, and society at large (45).

Pre-natal diagnosis of congenital heart defects produces an ethical dilemma for both parents and physician. The right to decide should be left to the parents, while the caregivers have to support them with nondirective counselling, with the information necessary for parental decision $(39,46)$.

When individuals have been asked about a choice for their own life, the preference was always for some life, even if short and with poor quality, than no life at all $(39,46)$.

Full information about a fetal congenital heart defects, particularly in the case of simple defects, has to be provided with all available data obtainable with the currently available treatments $(42,43)$. The way the family is perceiving the information received is certainly influenced by the modality used by the counsellor to transmit the information $(39,46)$.

\section{Conclusions}

One of the major achievements of pediatric medicine in the last 50 years is the increased understanding of the pathogenetic causal mechanisms of congenital heart defects as well as its treatment, and any resultant sequelae. In particular, for infants with congenital heart defects, the progress of the surgical treatment has allowed a huge increase in the proportion of these children that will reach adult life with a decent quality of life and social integration. Therefore, must be a considerable concern that universal pre-natal diagnosis widespread pregnancy interruption may obviate those gains. Furthermore, such a reduction in the post-natal population undergoing treatment may have a significantly deleterious effect on the experience and expertise of those involved in the care, which might conceivably produce a reduction in outcome quality which cannot be considered positively.

With all respect for the parental choices and the obligations to follow the national laws, however the feeling is the necessity to remark that our society is genuinely ambivalent.

\section{Acknowledgments}

Funding: None.

\section{Footnote}

Provenance and Peer Review: This article was commissioned by the editorial office, Translational Pediatrics for the series "Pre-natal Diagnosis in Congenital Heart Defects". The article has undergone external peer review.

Conflicts of Interest: The author has completed the ICMJE uniform disclosure form (available at http://dx.doi. org/10.21037/tp-20-141). The series "Pre-natal Diagnosis in Congenital Heart Defects" was commissioned by the editorial office without any funding or sponsorship. AFC served as the unpaid Guest Editor of the series, and serves as an unpaid editorial board member of Translational Pediatrics from Apr 2020 to Mar 2022. The author has no other conflicts of interest to declare.

Ethical Statement: The author is accountable for all aspects of the work in ensuring that questions related to the accuracy or integrity of any part of the work are appropriately investigated and resolved.

Open Access Statement: This is an Open Access article distributed in accordance with the Creative Commons Attribution-NonCommercial-NoDerivs 4.0 International License (CC BY-NC-ND 4.0), which permits the noncommercial replication and distribution of the article with the strict proviso that no changes or edits are made and the original work is properly cited (including links to both the formal publication through the relevant DOI and the license). See: https://creativecommons.org/licenses/by-nc-nd/4.0/.

\section{References}

1. Pinto NM, Keenan HT, Minich LL, et al. Barriers to prenatal detection of congenital heart disease: a population-based study. Ultrasound Obstet Gynecol 
2012;40:418-25.

2. Clur SA, Bilardo CM. Early detection of fetal cardiac abnormalities: how effective is it and how should we manage these patients? Prenat Diagn 2014;34:1235-45.

3. Bakker MK, Bergman JEH, Krikov S, et al. Prenatal diagnosis and prevalence of critical congenital heart defects: an international retrospective cohort study. BMJ Open 2019;9:e028139.

4. Tworetzky W, McElhinney DB, Reddy VM, et al. Improved surgical outcome after fetal diagnosis of hypoplastic left heart syndrome. Circulation 2001;103:1269-73.

5. Rychik J, Szwast A, Natarajan S, et al. Perinatal and early surgical outcome for the fetus with hypoplastic left heart syndrome: a 5-year single institutional experience. Ultrasound Obstet Gynecol 2010;36:465-70.

6. Axt-Fliedner R, Enzensberger C, Fass N, et al. Fetal diagnosis of hypoplastic left heart, associations and outcomes in the current era. Ultraschall Med 2012;33:E51-6.

7. Kawataki M. Ethical issues and decision-making in fetal cardiology. Pediatr Int 1999;41:733-6.

8. Vandvik IH, Førde R. Ethical issues in parental decisionmaking. An interview study of mothers of children with hypoplastic left heart syndrome. Acta Paediatr 2000;89:1129-33.

9. Barnes LL, Plotnikoff GA, Fox K, et al. Spirituality, religion, and pediatrics: intersecting worlds of healing. Pediatrics 2000;106:899-908.

10. Barnes LL, Plotnikoff GA. Fadiman and beyond--the dangers of extrapolation. Bioethics Forum 2001;17:32-40.

11. Rakow T. Differences in belief about likely outcomes account for differences in doctors' treatment preferences: but what accounts for the differences in belief? Qual Health Care 2001;10 Suppl 1:i44-9.

12. Kachaner J. Intractable neonatal heart diseases: a controversy. Arch Pediatr 2002;9 Suppl 1:49s-54s.

13. Gutgesell HP. What if it were your child? Am J Cardiol 2002;89:856.

14. Menahem S, Grimwade J. Pregnancy termination following prenatal diagnosis of serious heart disease in the fetus. Early Hum Dev 2003;73:71-8.

15. Menahem S, Grimwade J. Counselling strategies in the prenatal diagnosis of major heart abnormality. Heart Lung Circ 2004; 13:261-5.

16. Rempel GR, Cender LM, Lynam MJ, et al. Parents' perspectives on decision making after antenatal diagnosis of congenital heart disease. J Obstet Gynecol Neonatal Nurs 2004;33:64-70.
17. Menahem S, Grimwade J. Pre-natal counselling--helping couples make decisions following the diagnosis of severe heart disease. Early Hum Dev 2005;81:601-7.

18. Jacobs JP, Ungerleider RM, Tchervenkov CI, et al. Opinions from the audience response survey at the first joint meeting of the Congenital Heart Surgeons' Society and the European Congenital Heart Surgeons Association. Semin Thorac Cardiovasc Surg Pediatr Card Surg Annu 2005;198-217.

19. Yeu BK, Chalmers R, Shekleton P, et al. Fetal cardiac diagnosis and its influence on the pregnancy and newborn--a tertiary centre experience. Fetal Diagn Ther 2008;24:241-5.

20. Prsa M, Holly CD, Carnevale FA, et al. Attitudes and practices of cardiologists and surgeons who manage HLHS. Pediatrics 2010;125:e625-30.

21. Mavroudis C, Mavroudis CD, Farrell RM, et al. Informed consent, bioethical equipoise, and hypoplastic left heart syndrome. Cardiol Young 2011;21 Suppl 2:133-40.

22. Murtuza B, Elliott MJ. Changing attitudes to the management of hypoplastic left heart syndrome: a European perspective. Cardiol Young 2011;21 Suppl 2:148-58.

23. Menahem $\mathrm{S}$. Ethical questions arising from counselling in fetal complex congenital heart disease. Monash Bioeth Rev 2012;30:62-7.

24. McKechnie AC, Pridham K. Preparing heart and mind following prenatal diagnosis of complex congenital heart defect. Qual Health Res 2012;22:1694-706.

25. Hilton-Kamm D, Chang RK, Sklansky M. Prenatal diagnosis of hypoplastic left heart syndrome: impact of counseling patterns on parental perceptions and decisions regarding termination of pregnancy. Pediatr Cardiol 2012;33:1402-10.

26. Dean PN, McHugh KE, Conaway MR, et al. Effects of race, ethnicity, and gender on surgical mortality in hypoplastic left heart syndrome. Pediatr Cardiol 2013;34:1829-36.

27. Caldera K, Ha D, Menahem S. The development of a CDROM: an aid to fetal cardiac diagnosis and counseling. Fetal Diagn Ther 2013;33:61-4.

28. Nell S, Wijngaarde CA, Pistorius LR, et al. Fetal heart disease: severity, associated anomalies and parental decision. Fetal Diagn Ther 2013;33:235-40.

29. Bevilacqua F, Palatta S, Mirante N, et al. Birth of a child with congenital heart disease: emotional reactions of mothers and fathers according to time of diagnosis. $\mathrm{J}$ Matern Fetal Neonatal Med 2013;26:1249-53. 
30. Corno A, Becker AE, Bulterijs AH, et al. Univentricular heart: can we alter the natural history? Ann Thorac Surg 1982;34:716-27.

31. Corno AF. Surgery for congenital heart disease. Curr Opin Cardiol 2000;15:238-43.

32. Atz AM, Travison TG, McCrindle BW, et al. Cardiac performance and quality of life in patients who have undergone the Fontan procedure with and without prior superior cavopulmonary connection. Cardiol Young 2013;23:335-43.

33. d'Udekem Y, Iyengar AJ, Galati JC, et al. Redefining expectations of long-term survival after the Fontan procedure: twenty-five years of follow-up from the entire population of Australia and New Zealand. Circulation 2014;130:S32-8.

34. Arnold RR, Loukanov T, Gorenflo M. Hypoplastic left heart syndrome - unresolved issues. Front Pediatr 2014;2:125.

35. Rossano JW, Shaddy RE. Heart transplant after the Fontan operation. Cardiol Young 2013;23:841-6.

36. Iyengar AJ, Sharma VJ, Weintraub RG, et al. Surgical strategies to facilitate heart transplantation in children after failed univentricular palliations: the role of advanced intraoperative surgical preparation. Eur J Cardiothorac Surg 2014;46:480-5; discussion 485.

37. De Rita F, Hasan A, Haynes S, et al. Mechanical cardiac support in children with congenital heart disease with intention to bridge to heart transplantation $†$. Eur J Cardiothorac Surg 2014;46:656-62; discussion 662.

38. Alsoufi B, Slesnick T, McCracken C, et al. Current outcomes of the Norwood operation in patients with

Cite this article as: Corno AF. Ethical issues after pre-natal diagnosis. Transl Pediatr 2021;10(8):2235-2240. doi: 10.21037/ tp-20-141 single-ventricle malformations other than hypoplastic left heart syndrome. World J Pediatr Congenit Heart Surg 2015;6:46-52.

39. Corno AF. "Functionally" univentricular hearts: impact of pre-natal diagnosis. Front Pediatr 2015;3:15.

40. Lytzen R, Vejlstrup N, Bjerre J, et al. Live-Born Major Congenital Heart Disease in Denmark: Incidence, Detection Rate, and Termination of Pregnancy Rate From 1996 to 2013. JAMA Cardiol 2018;3:829-37.

41. Bensemlali M, Stirnemann J, Le Bidois J, et al. Discordances Between Pre-Natal and Post-Natal Diagnoses of Congenital Heart Diseases and Impact on Care Strategies. J Am Coll Cardiol 2016;68:921-30.

42. O'Brien SM, Clarke DR, Jacobs JP, et al. An empirically based tool for analyzing mortality associated with congenital heart surgery. J Thorac Cardiovasc Surg 2009;138:1139-53.

43. Jacobs JP, Jacobs ML, Maruszewski B, et al. Initial application in the EACTS and STS Congenital Heart Surgery Databases of an empirically derived methodology of complexity adjustment to evaluate surgical case mix and results. Eur J Cardiothorac Surg 2012;42:775-9; discussion 779-80.

44. Huhta JC. Uses and abuses of fetal echocardiography: a pediatric cardiologist's view. J Am Coll Cardiol 1986;8:451-8.

45. Squarcia U. Fetal diagnosis of congenital cardiac malformations: a challenge for physicians as well as parents. Cardiol Young 1996;6:256-7.

46. Shinebourne EA, Carvalho JS. Ethics of fetal echocardiography. Cardiol Young 1996;6:261-3. 